\title{
Avaliação Nacional da Alfabetização: síntese sobre os resultados das escolas associados a variáveis socioeducacionais
}

José Francisco Soares

Luana Bergmann

\section{Resumo}

O analfabetismo, no Brasil, permanece uma séria questão nacional, apesar de o acesso à escola ter deixado de ser um problema abrangente. O artigo apresenta uma síntese da Avaliação Nacional da Alfabetização (ANA), avaliação externa realizada em larga escala pelo governo federal brasileiro nas escolas públicas do País entre os anos de 2013 e 2016, tendo como público-alvo os estudantes do $3^{\circ}$ ano do ensino fundamental da educação básica. Expõe um panorama sobre o método adotado na avaliação, apontando os principais conceitos e instrumentos que estruturaram a iniciativa. Sumariza os resultados nacionais demonstrados pelo público-alvo da edição 2016 da ANA, e os associa a um conjunto de variáveis escolares e sociais relevantes. Constata que as características do alunado, da infraestrutura, da dependência administrativa e da complexidade das escolas, assim como a formação dos docentes, criam grupos de escolas com enormes diferenças em termos da proficiência medida pelos testes da ANA.

Palavras-chave: alfabetização; avaliação externa; desigualdades educacionais. 


\section{Abstract \\ Avaliação Nacional da Alfabetização: synthesis on schools results associated to socio-educational variables}

Illiteracy in Brazil remains a serious national issue, even though access to school is no longer a comprehensive problem. This article presents a synthesis of the Avaliação Nacional da Alfabetização (ANA), an external evaluation carried out on a large scale by the Brazilian federal government in public schools between the years 2013 and 2016, targeting students in the 3rd year of elementary school. It presents an overview of the method adopted in the evaluation, pointing out the main concepts and instruments that have structured the initiative. It summarizes the national results demonstrated by the students of the 2016 ANA edition, and associates them with a set of relevant school and social variables. The article finds that the characteristics of students, infrastructure, administrative dependency and complexity of schools, as well as the training of teachers, create groups of schools with huge differences in terms of proficiency measured by ANA tests.

Keywords: educational inequalities; external evaluation; literacy.

\section{Resumen \\ Evaluación Nacional de la Alfabetización: síntesis sobre los resultados de las escuelas asociados a variables socioeducativas}

El analfabetismo, en Brasil, sigue siendo un problema nacional grave, aunque el acceso a la escuela haya dejado de ser un problema abarcador. El artículo presenta una síntesis de la Evaluación Nacional de la Alfabetización (Avaliação Nacional da Alfabetização - ANA), evaluación externa realizada a gran escala por el gobierno federal brasileño en las escuelas públicas del país entre los años 2013 y 2016, dirigida a estudiantes del tercer año de primaria. Presenta un panorama sobre el método adoptado en la evaluación, señalando los principales conceptos e instrumentos que estructuraron la iniciativa. Resume los resultados nacionales demostrados por el público objetivo de la edición 2016 de la ANA y los asocia con un conjunto de variables escolares y sociales relevantes. Constata que las características de los estudiantes, de la infraestructura, de la dependencia administrativa y de la complejidad de las escuelas, así como la formación de los docentes, crean grupos de escuelas con grandes diferencias en términos de la competencia medida por los test ANA.

Palabras clave: alfabetización; evaluación externa; desigualdades educativas. 


\section{Introdução}

Só muito lentamente se consolidou no Brasil a importância da educação como um direito humano fundamental para o desenvolvimento de cada pessoa, seu exercício da cidadania e sua inserção no mundo do trabalho. Durante longos anos, o Brasil adotou a posição cômoda de excluir os analfabetos da vida democrática, negando-lhes o direito ao voto. É sintomático que a proibição do voto do analfabeto, introduzida pela Lei Saraiva, de 1882, no final do Império, tenha se mantido inalterada durante mais de cem anos de República, até a Constituição de 1988. Como diz Paiva (1990, p. 9), "ao longo de grande parte da nossa história essa questão [do analfabetismo] não esteve posta".

No entanto, a necessidade de alfabetizar a população não esteve completamente ausente das políticas públicas. Ao longo do século 20, houve muitas iniciativas: a Campanha de Educação de Adolescentes e Adultos, de 1947; a Campanha Nacional de Erradicação do Analfabetismo, de 1958; o Programa Nacional de Alfabetização, baseado no método Paulo Freire, de 1964; o Movimento Brasileiro de Alfabetização (Mobral), entre os anos de 1968 e 1978; a Fundação Nacional de Educação de Jovens e Adultos (Educar), de 1985; o Programa Nacional de Alfabetização e Cidadania (Pnac), de 1990; o Plano Decenal de Educação para Todos, de 1993; e, no final do último século, o Programa de Alfabetização Solidária, de 1997.

Como resultado de todas essas iniciativas e do progressivo acesso à escola de educação básica para as crianças, o nível de analfabetismo da população brasileira maior de 15 anos, medido nos censos demográficos decenais, caiu sistematicamente durante o século 20, saindo de 65\% em 1920, atingindo 51\% em 1950, chegando a 25\% em 1980 e a 9,6\% em 2010.

Com essa queda progressiva, a partir do final dos anos 1990, a discussão sobre alfabetização passou a contemplar um novo problema. Muitos estudantes, embora frequentando a escola durante vários anos, não estavam plenamente alfabetizados, ou seja, a maior exclusão passou a ser operada dentro da escola. Ribeiro (1991) cunhou a expressão "pedagogia da repetência" e trouxe para o debate educacional a estratégia de exclusão escolar, amplamente difundida, de reprovação dos estudantes nos anos iniciais de escolarização. Isso ensejou a criação dos ciclos de alfabetização com a dupla função: a de garantir a permanência da criança na escola e a de sua adequada alfabetização. Nos anos 2000, com praticamente todas as crianças de 6 anos de idade na escola, foi natural que a meta se tornasse: obter a alfabetização dessas crianças em um tempo adequado.

É nesse contexto que o governo federal instituiu o Pacto Nacional pela Alfabetização na Idade Certa (Pnaic), por meio da Portaria no 867/2012 do Ministério da Educação (MEC), que, considerando a necessidade de se conhecer com maior precisão o nível de alfabetização dos estudantes brasileiros, criou uma avaliação externa em larga escala denominada Avaliação Nacional da Alfabetização (ANA), cuja implementação foi delegada ao Instituto Nacional de Estudos e Pesquisas Educacionais Anísio Teixeira (Inep). No ano seguinte, meses antes da realização da edição-piloto da ANA, o MEC publicou a Portaria MEC nº 482/2013, por meio da qual 
incorporava essa inédita avaliação de alfabetização ao Sistema de Avaliação da Educação Básica (Saeb), ampliando a abrangência desse sistema existente desde a década de 1990 no Brasil.

\section{Conceitos, instrumentos e metodologia da avaliação}

O critério para verificar, nos censos demográficos, se um indivíduo está ou não alfabetizado variou ao longo dos anos. Como detalhado por Ferraro (2002, p. 31), a referência evoluiu do "saber assinar o próprio nome" para "ler e escrever um bilhete simples, em um idioma qualquer", forma que, na sua essência, continua até o censo demográfico mais recente, realizado em 2010, e em todas as pesquisas anuais.

Embora informativa para estudos populacionais gerais, essa definição não produz informação útil para subsidiar políticas públicas específicas e nem o projeto pedagógico das escolas. Assim sendo, para organizar uma avaliação externa, é necessário definir muito mais claramente em que consiste estar alfabetizado. Diante disso, coube ao Inep, por meio de "exame periódico específico", operacionalizar o critério de verificação da meta central do Pnaic: "alfabetizar as crianças até, no máximo, os oito anos de idade, ao final do $3^{\circ}$ ano do ensino fundamental".

Para estar alfabetizado, o estudante deve demonstrar domínio de várias capacidades. Isso está evidente no infográfico introduzido por Scarborough (2001), referido como read in grope, e metaforicamente na expressão terminar de "aprender a ler" para começar a "ler para aprender". Nos documentos que orientam a ANA, o Inep reservou o termo "alfabetização" para se referir ao processo de "apreensão do código alfabético" e adotou o termo "letramento" como o processo de "compreensão dos significados e seus usos sociais em diferentes contextos" (Brasil. Inep, 2013, p. 9).

No entanto, enfatize-se que esses dois processos são considerados como partes de um único continuum. O documento do Inep esclarece:

O emprego dos termos "alfabetização" e "letramento" [...] coaduna-se com as discussões acadêmicas conduzidas nos últimos anos, as quais consolidaram a ideia de articulação entre essas noções, considerando que, embora sejam dois processos distintos, são complementares e importantes no processo de aquisição da língua escrita. Desse modo, entende-se que o processo de apreensão do código alfabético deva ser associado à compreensão dos significados e seus usos sociais em diferentes contextos. (Brasil. Inep, 2013, p. 9).

A ênfase no letramento também está de acordo com recomendações internacionais. A Unesco definiu "letramento", tradução do termo literacy, em inglês, da seguinte maneira:

Letramento [literacy] é a capacidade de identificar, entender, interpretar, criar, comunicar e computar, usando materiais impressos e escritos (e visuais) associados a contextos variados. O letramento envolve um continuum de aprendizados que permitem a um indivíduo alcançar seus objetivos, desenvolver seus conhecimentos e talentos e participar plenamente da sociedade em geral. (Unesco, 2004). 
Ainda em termos internacionais, o Pirls, sigla em inglês do Estudo Internacional do Progresso em Compreensão Leitora, usa também o conceito de letramento, referido como literacia na tradução portuguesa, para especificar o que é medido pelo teste:

[Literacia de leitura] é a capacidade de compreender e utilizar as formas de linguagem escrita requeridas pela sociedade ou valorizadas pelo indivíduo. Os leitores conseguem atribuir sentido a textos com formatos variados. Leem para aprender, para participar em comunidades de leitores, na escola e na vida quotidiana, e leem por prazer. (Mullis; Martin, 2015, p. 12).

A definição do conceito de "alfabetização" impacta não só os testes, mas também a organização dos processos de ensino. Está bem estabelecido que a criança deve ter instrução sobre o sistema de escrita alfabético, como as relações entre fonemas e grafemas, e também sobre as práticas sociais da língua escrita. Cada um desses aprendizados exige pedagogias diferentes para que cada criança adquira essas capacidades. Essa é uma questão detalhadamente considerada por Soares (2016).

O Inep estruturou a ANA como uma avaliação em larga escala, de alcance censitário, para medir os níveis de alfabetização de todos os estudantes do $3^{\circ}$ ano do ensino fundamental matriculados nas redes públicas, ao final do que se considerava, à época, o ciclo de alfabetização. Esse público-alvo é composto, portanto, em sua maioria, por crianças de 8 anos de idade completos e, por outra parte, de estudantes que já possuem mais de 9 anos. Foram avaliados os estudantes das escolas públicas brasileiras com pelo menos 10 alunos matriculados no $3^{\circ}$ ano do ensino fundamental.

A Matriz de Referência de Língua Portuguesa apresentou-se com dois eixos estruturantes: Leitura e Escrita. Há 12 habilidades $(\mathrm{H})$ ao total - nove no eixo de Leitura e três no eixo de Escrita:

\section{Eixo de Leitura:}

Hl. Ler palavras com estrutura silábica canônica.

H2. Ler palavras com estrutura silábica não canônica.

H3. Reconhecer a finalidade do texto.

H4. Localizar informações explícitas em textos.

H5. Compreender os sentidos de palavras e expressões em textos.

H6. Realizar inferências a partir da leitura de textos verbais.

H7. Realizar inferências a partir da leitura de textos que articulem a linguagem verbal e não verbal.

H8. Identificar o assunto de um texto.

H9. Estabelecer relações entre partes de um texto marcadas por elementos coesivos.

Eixo de Escrita:

H10. Grafar palavras com correspondências regulares diretas.

H11. Grafar palavras com correspondências regulares contextuais entre letras ou grupos de letras e seu valor sonoro.

H12. Produzir um texto a partir de uma situação dada. 
A Matriz de Língua Portuguesa (LP) da ANA se concentra na verificação de objetivos relacionados à leitura e compreensão de textos, com quase $60 \%$ das habilidades registradas. Verifica também a capacidade de produção escrita dos estudantes, com 25\% dos objetivos, e, por fim, contempla a leitura de palavras canônicas e não canônicas, com pouco mais de 15\% dos objetivos incluídos na matriz. O peso dado à leitura e à compreensão de textos, ressaltado pela Matriz de LP da ANA, dialogava coerentemente com as expectativas gerais em torno do aprendizado de estudantes que já haviam percorrido praticamente três anos de escolarização.

Tomando por referência a Matriz de LP da ANA, o Inep elaborou um conjunto de itens com capacidade de aferir o domínio de cada um dos objetivos de aprendizagem por parte dos estudantes. Os testes de LP aplicados pelo Inep nas edições da ANA compunham-se tanto de itens de resposta objetiva (de múltipla escolha) como de itens de resposta construída (itens de escrita ou discursivos). Em LP, cada criança participante da avaliação respondia a 20 itens de resposta objetiva e a três itens de resposta construída.

Os itens de resposta objetiva organizavam-se em duas categorias distintas. Por um lado, foram apresentados itens que exigiam que as crianças reconhecessem uma figura e, em seguida, escolhessem a alternativa que registrava a palavra que descrevia a figura. Eram itens que buscavam aferir as habilidades H1 e H2 da Matriz de Referência de LP, respectivamente, "ler palavras com estrutura canônica" e "ler palavras com estrutura não-canônica". Cada criança respondia a dois itens desses - um ligado à H1 e outro ligado à H2.

A Figura 1 mostra dois exemplos reais desses itens, aplicados nas edições da ANA entre 2013 e 2016 :

Veja a figura:
$\begin{array}{ll}\text { (A) PIJAMA } & \text { (A) JATINHO } \\ \text { (B) PILOTO } & \text { (B) JAQUINHA } \\ \text { (D) PIRATA } & \text { (C) JOANINHA } \\ & \text { (D) JOÃOZINHO }\end{array}$

Figura 1 - Exemplos de itens que aferiram a leitura das palavras

Fonte: Relatório 2013-2014, volume 1 (Brasil. Inep, 2015a, p. 39-40). 
Além dos itens de leitura de palavras referenciados, incluíram-se, entre os itens de resposta objetiva, outros que verificavam o domínio de objetivos de aprendizagem ligados à leitura e à compreensão de textos, desde os mais simples, como localizar informação explícita no texto, até os mais complexos, como fazer inferências.

A Figura 2 contém exemplos reais desses itens, aplicados nas edições da ANA entre 2013 e 2016, incluídos para verificar o domínio dos estudantes de sua capacidade de localizar informação explícita no texto (H4).

Leia o texto:

\section{A festa no céu}

Naquela noite ia ter uma grande festa no céu, mas os animais sem asas estavam muito tristes porque não poderiam ir. Imaginavam a música e a comida que não iriam aproveitar. Mas a tartaruga decidiu ir à festa, e teve uma ideia genial! Será que ela vai conseguir? LAGO, A. A festa no céu. São Paulo: Melhoramentos, 2005 (adaptado).

Quando ia acontecer a festa no céu?
(A) À noite.
(B) De manhã
(C) À tarde.
(D) De madrugada.

\section{Figura 2 - Exemplo de item que aferiu a capacidade de localizar informações no texto}

Fonte: Relatório 2013-2014, volume 1 (Brasil. Inep, 2015a, p. 40).

Os itens de resposta construída, por sua vez, pertencem a duas categorias: itens de escrita de palavra e itens de escrita de texto. Os itens de escrita de palavras exigiam que a criança escrevesse uma palavra canônica e outra não canônica, ambas com base em uma figura apresentada no item. O item de texto, a seu turno, exigia que a criança produzisse um pequeno texto com base em trecho motivador. Observe, na Figura 3, exemplos reais desses itens aplicados nas edições da ANA entre 2013 e 2016 com respostas típicas obtidas.

A edição da ANA 2013 tornou-se uma aplicação-piloto, cujos procedimentos de aplicação foram revisados e fixados nas edições de 2014 e 2016. Adotou-se o mês de novembro como época de aplicação, e os testes foram realizados em dois dias. No primeiro dia de aplicação dos instrumentos, os estudantes respondiam ao teste de LP por até 90 minutos. Os primeiros 60 minutos eram destinados aos itens de resposta objetiva, e os 30 minutos finais estavam reservados para que as crianças respondessem aos itens de resposta construída. No segundo dia, nas aplicações de 2014 e 2016, os estudantes respondiam ao teste de Matemática em até 60 minutos. Ao final da aplicação dos testes, o aplicador designado preenchia o Cartão de Respostas (CR) de cada aluno. Todo o material era colocado em envelopes próprios e encaminhado às instituições contratadas pelo Inep para realizar o processamento das informações coletadas. 


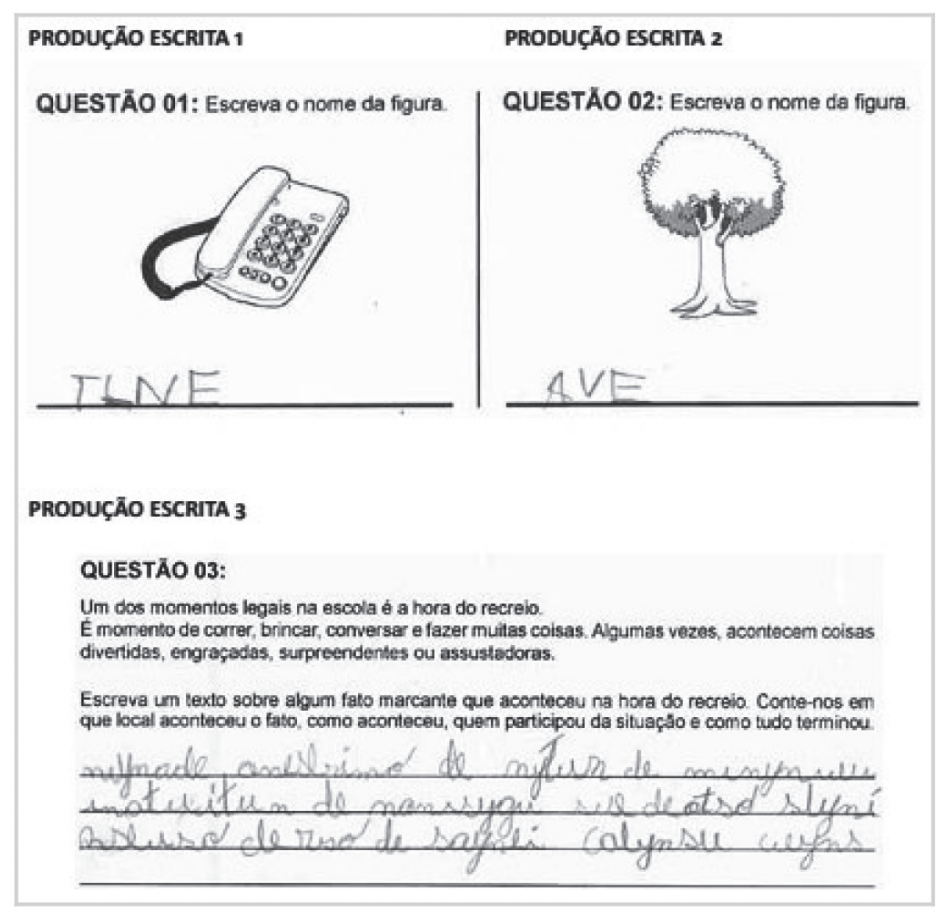

Figura 3 - Exemplos de itens de escrita

Fonte: Relatório Saeb/ANA 2016 (Brasil. Inep, 2018, p. 42).

A apuração dos resultados começava com a leitura ótica dos CRs dos alunos. Ao final da referida leitura, compunha-se uma enorme base de dados, com informações de mais de 2,5 milhões de estudantes, a partir da qual se realizaram as análises estatísticas e pedagógicas das informações. A Teoria de Resposta ao Item e a Teoria Clássica dos Testes davam sustentação teórico-metodológica a essas análises.

Ao final do processo, estruturam-se as Escalas de Proficiência - instrumentos que orientam a interpretação pedagógica dos resultados da avaliação. No caso de LP, para o eixo de Leitura, o Inep dividiu a escala em quatro níveis diferentes e progressivos. Cada nível foi descrito considerando os itens nele alocados, indicando o estágio de alfabetização dos estudantes. O Quadro 1 apresenta a escala estabelecida.

O Inep optou por apresentar os resultados da ANA de duas formas: uma síntese numérica do desempenho de cada estudante nos testes, que ensejou o cálculo de proficiências médias por escolas, municípios e estados; e o percentual de estudantes em cada um dos quatro níveis de proficiência em que a escala foi dividida. O uso de níveis de proficiência é particularmente importante para as decisões pedagógicas e, por isso, é usado em avaliações educacionais e nunca em exames. 
Quadro 1 - Escala de Proficiência em Leitura da ANA

\begin{tabular}{|c|c|}
\hline \multicolumn{2}{|r|}{ ESCALA DE PROFICIÊNCIA EM LEITURA } \\
\hline NÍVEL & DESCRIÇÃO \\
\hline $\begin{array}{l}\text { NÍVEL } 1 \\
\text { (até } 425 \\
\text { pontos) }\end{array}$ & $\begin{array}{l}\text { Nesse nível, os estudantes provavelmente são capazes de: } \\
\checkmark \text { Ler palavras com estrutura silábica canônica, não canônica e ainda que } \\
\text { alternem sílabas canônicas e não canônicas. }\end{array}$ \\
\hline $\begin{array}{l}\text { NÍVEL } 2 \\
\text { (maior } \\
\text { que } 425 \\
\text { até } 525 \\
\text { pontos) }\end{array}$ & $\begin{array}{l}\text { Além das habilidades descritas no nível anterior, os estudantes provavel- } \\
\text { mente são capazes de: } \\
\checkmark \text { Localizar informações explícitas em textos curtos como piada, parlenda, poema, } \\
\text { quadrinho, fragmentos de narrativas e de curiosidade científica; em textos de } \\
\text { maior extensão, quando a informação está localizada na primeira linha do texto. } \\
\checkmark \text { Reconhecer a finalidade de texto como convite, cartaz, receita, bilhete, } \\
\text { anúncio com ou sem apoio de imagem. } \\
\checkmark \text { Identificar assunto de um cartaz apresentado em sua forma original e ainda } \\
\text { em textos cujo assunto pode ser identificado no título ou na primeira linha. } \\
\checkmark \text { Inferir sentido em piada e em história em quadrinhos que articula } \\
\text { linguagem verbal e não verbal. }\end{array}$ \\
\hline $\begin{array}{l}\text { NÍVEL } 3 \\
\text { (maior } \\
\text { que } 525 \\
\text { até } 625 \\
\text { pontos) }\end{array}$ & $\begin{array}{l}\text { Além das habilidades descritas nos níveis anteriores, os estudantes provavel- } \\
\text { mente são capazes de: } \\
\checkmark \text { Localizar informação explícita em textos de maior extensão, como } \\
\text { fragmento de literatura infantil, lenda, cantiga folclórica e poema, quando a } \\
\text { informação está localizada no meio ou no final do texto. } \\
\checkmark \text { Identificar o referente de um pronome pessoal do caso reto em textos como } \\
\text { tirinha e poema narrativo. } \\
\checkmark \text { Inferir relação de causa e consequência em textos exclusivamente verbais - } \\
\text { piada, fábula, fragmentos de textos de literatura infantil e texto de curiosidade } \\
\text { científica - com base na progressão textual; e em textos que articulam a } \\
\text { linguagem verbal e não verbal - tirinha; sentido em história em quadrinhos } \\
\text { que articula linguagem verbal e não verbal com vocabulário específico de } \\
\text { textos de divulgação científica ou que exige conhecimento intertextual de } \\
\text { narrativas infantis; o assunto de texto de extensão média de divulgação } \\
\text { científica para estudantes, com base nos elementos que aparecem no início do } \\
\text { texto; o significado de expressão de linguagem figurada em textos como poema } \\
\text { narrativo, fragmentos de literatura infantil, de curiosidade científica e tirinha. }\end{array}$ \\
\hline $\begin{array}{l}\text { NÍVEL } 4 \\
\text { (maior } \\
\text { que } 625 \\
\text { pontos) }\end{array}$ & $\begin{array}{l}\text { Além das habilidades descritas nos níveis anteriores, os estudantes provavel- } \\
\text { mente são capazes de: } \\
\checkmark \text { Reconhecer relação de tempo em texto verbal e os participantes de um } \\
\text { diálogo em uma entrevista ficcional. } \\
\checkmark \text { Identificar o referente de pronome possessivo em poema; o referente de } \\
\text { advérbio de lugar em reportagem; o referente de expressão formada por } \\
\text { pronome demonstrativo em fragmento de texto de divulgação científica para } \\
\text { o público infantil. } \\
\checkmark \text { Inferir sentido em fragmento de conto; sentido de palavra em fragmento } \\
\text { de texto de literatura infantil; assunto em texto de extensão média ou longa, } \\
\text { considerando elementos que aparecem ao longo do texto, em gêneros como } \\
\text { divulgação científica, curiosidade histórica para estudante e biografia. }\end{array}$ \\
\hline
\end{tabular}


Preferiu também o Inep não dar etiquetas valorativas aos níveis em que divide a proficiência dos estudantes. No entanto, o uso de quatro níveis é frequentemente associado a etiquetas que orientam o trabalho pedagógico, como Abaixo do Básico, Básico, Adequado e Avançado. Essas etiquetas, ou outras similares, sugerem intervenções pedagógicas para os estudantes classificados em cada um desses níveis. Assim, os estudantes classificados no nível 1 aprenderam apenas as habilidades elementares e precisam de oportunidades de recuperação; os do nível 2 aprenderam apenas algumas das habilidades da matriz e, assim sendo, precisam de intervenções pedagógicas que lhes permitam expandir os seus aprendizados. Os estudantes classificados no nível 3 aprenderam o que deles se esperava, mas podem ter oportunidades de aprofundamento de seu domínio das habilidades e, finalmente, os que foram classificados no nível 4, tipicamente avançado, podem ser colocados diante de novos desafios que ultrapassem o esperado.

O diagnóstico pedagógico, obtido usando-se o percentual de estudantes em cada um dos níveis, pode ser diferente do diagnóstico obtido com médias. Isso ocorre com frequência no debate educacional brasileiro, quando adotado unicamente o Índice de Desenvolvimento da Educação Básica (Ideb). Esse índice permite, implicitamente, que o bom desempenho de alguns poucos alunos compense o mau desempenho de muitos alunos. Ou seja, diagnósticos educacionais baseados exclusivamente no Ideb podem, às vezes, sugerir que uma escola não tem problemas, quando, na realidade, há muitos estudantes com baixo aprendizado. Assim sendo, a ênfase dada pelos relatórios da ANA é uma opção metodológica que faz adequadamente a tradução dos escores numéricos para uma linguagem pedagógica que pode ser usada na rotina de cada rede de ensino e escola.

\section{Os resultados nacionais da ANA 2016 e sua associação com variáveis socioeducacionais relevantes}

Na última edição da ANA, aplicada em 2016, ficou demonstrado que mais de $50 \%$ dos alunos de $3^{\circ}$ ano do ensino fundamental matriculados em escolas públicas brasileiras haviam alcançado no máximo o nível 2 de proficiência em Leitura. O Quadro 2 apresenta os detalhes.

\section{Quadro 2 - Percentual de estudantes brasileiros em cada um dos níveis de proficiência em Leitura da ANA 2016}

\begin{tabular}{|l|c|c|c|c|c|c|}
\hline Avaliação & Ano & Área & Nível 1 & Nível 2 & Nível 3 & Nível 4 \\
\hline ANA & 2016 & Leitura & $22 \%$ & $33 \%$ & $32 \%$ & $13 \%$ \\
\hline
\end{tabular}

Fonte: Elaboração própria com base no Relatório Saeb/ANA 2016 (Brasil. Inep, 2018).

O objeto desta seção é verificar a associação entre os resultados da ANA e um conjunto de seis fatores que caracterizam as escolas: (i) nível socioeconômico dos alunos, (ii) qualificação docente, (iii) dependência administrativa das escolas, (iv) complexidade das escolas, (v) salário docente e (vi) infraestrutura das escolas. 
Os três primeiros indicadores são informações sistematizadas rotineiramente pelo Inep e incluídas nos microdados da ANA, usados nesta análise. O quarto indicador - complexidade das escolas -, apesar de também calculado pelo Inep, não estava disponível nos microdados e, por isso, foi agregado à base de dados preparada para esta análise. Essa base de dados incluiu também o salário dos docentes de cada escola. Esse dado é proveniente de pesquisa realizada pelo Inep em 2014, que associou a informação da Relação Anual de Informações Sociais aos dados do Censo Escolar de 2014, obtendo, assim, uma informação completa e fidedigna sobre os salários dos docentes de cada escola. Finalmente, a informação sobre a infraestrutura das escolas foi obtida em pesquisa recente da Unesco, feita com os dados do censo escolar.

A decisão de juntar diferentes indicadores de diferentes pesquisas, com o intuito de considerar toda a evidência disponível, implicou incluir na base de dados usada neste artigo escolas com ausência de informação em alguns indicadores. Para considerar essa característica dos dados, cada um desses seis fatores foi discretizado em duas ou três categorias, e uma categoria foi acrescentada contendo as escolas com dados ausentes.

Além disso, cabe observar que nem todos os indicadores empregados são relativos a anos calendários exatamente iguais ao ano do resultado da ANA 2016. Assim, as associações mostradas são relevantes, se é correta a hipótese de que esses indicadores não mudaram ao longo dos anos. Trata-se de uma hipótese razoável, tendo em vista a proximidade dos anos calendários envolvidos na coleta dos dados para a construção dos diferentes indicadores.

A idade dos estudantes que participaram da ANA impediu a coleta individual, mediante questionários contextuais, de seus dados sociodemográficos.

Nossa primeira análise associada teve como foco o indicador de Nível Socioeconômico (NSE) das escolas avaliadas pela ANA. Há uma ampla literatura nacional mostrando, com dados nacionais, que os estudantes das escolas que congregam apenas alunos de NSE mais alto têm especial vantagem (Soares; Alves; Xavier, 2016). O Inep produz um indicador de NSE elaborado com as informações obtidas pelas respostas dos estudantes nos questionários contextuais do Saeb/ Prova Brasil. ${ }^{1}$ No entanto, muitas escolas incluídas na ANA não participaram do Saeb/Prova Brasil e, portanto, seu NSE não está na base de dados publicada pelo Inep. O NSE divulgado foi agregado em três categorias. O nível baixo é constituído dos níveis originais 1, 2 e 3; o nível médio, pela categoria 4; e o nível alto, pelas categorias 5, 6 e 7 .

Em segundo lugar, tomamos as informações sobre a infraestrutura das escolas. A Unesco divulgou recentemente o estudo Qualidade da infraestrutura das escolas públicas do ensino fundamental no Brasil, que introduz um indicador da infraestrutura das escolas, especialmente completo. Esse indicador foi discretizado em três categorias. $^{2}$

\footnotetext{
${ }^{1}$ Para desenvolvimentos recentes sobre a questão, no âmbito do Inep, ver Barros et al. (2019).

${ }^{2}$ Obtidas pela metodologia KMEANS do SPSS 20.
} 
Em seguida, analisamos o indicador denominado de "complexidade da gestão da escola", que agrega informações sobre o tamanho da escola, em termos do número de estudantes, e as etapas oferecidas. Esse indicador passou a ser calculado rotineiramente pelo Inep a partir de 2015. Para a associação com os resultados da ANA, o indicador foi discretizado em apenas dois níveis. Os níveis originais 1, 2, 3 e 4 constituíram o nível denominado Baixo; e os níveis 5 e 6, o nível denominado Alto.

O quarto fator relevante foi a Qualificação Docente. O Inep, baseando-se nos dados do censo escolar, criou um indicador da adequação da formação docente. Os docentes são considerados com formação adequada se têm licenciatura na área em que lecionam. Assim, para serem alfabetizadores, precisam ter a formação em pedagogia em nível superior. Esse indicador foi discretizado em três níveis. ${ }^{3}$

A variável de Dependência Administrativa das escolas também foi analisada. A legislação nacional estabelece que o ensino fundamental é de responsabilidade compartilhada dos municípios e estados. Assim sendo, em muitos estados, existem escolas estaduais e municipais atendendo aos estudantes da primeira etapa do ensino fundamental. A análise mostra que os estudantes das escolas estaduais têm melhor desempenho que os das municipais e ambas com resultados muito piores que os das escolas federais, que são, entretanto, poucas.

Em 2014, o Inep fez um detalhado estudo sobre o salário dos docentes. Cada docente presente no censo escolar foi identificado na Relação Anual de Informações Sociais (Rais), em que os empregadores públicos e privados registram os salários efetivamente pagos. O estudo do Inep exclui as informações aberrantes, produtos de claros erros de registro ou que correspondem a pagamentos específicos e não regulares. Para fins de comparabilidade, entretanto, os salários praticados foram transformados em salários correspondentes a 40 horas semanais. Isso, embora criando um dado de grande valor para o planejamento financeiro de cada município, gera um problema para a análise de resultados. Os professores podem, em princípio, se sentir mais motivados com maiores salários. Mas, para que essa motivação ocorra, contam os salários reais que os docentes recebem, e não um salário hipotético por um tempo contratual que não praticam. Por isso, esse dado não foi utilizado para as associações.

Considerando que todos esses cinco fatores agem concomitantemente na produção de resultados, as tabelas relacionando o resultado com cada fator isoladamente mostrariam resultados que, de modo inadequado, poderiam sugerir que as diferenças observadas seriam devidas apenas ao indicador considerado na tabela. Para evitar esse tipo de análise, todos os indicadores podem ser associados à média das proficiências dos estudantes por intermédio de um modelo de regressão. Com esse fim, foram criadas variáveis indicadoras para cada um dos fatores considerados nas tabelas, tomando-se sempre a categoria mais alta como referência. Os resultados da regressão são apresentados no Quadro 3. Os coeficientes são a expressão do efeito de cada variável, depois de retirado o efeito das outras variáveis incluídas.

\footnotetext{
${ }^{3}$ Usando o procedimento KMEANS do SPSS 20. Para esse indicador não há dados ausentes, considerando que é calculado com informações obtidas pelo censo escolar.
} 
Quadro 3 - Coeficientes do modelo de Regressão Múltipla: variável independente - média do desempenho dos estudantes de cada escola em Leitura na ANA 2016

\begin{tabular}{|c|c|c|c|c|}
\hline & Coeficiente & Desvio-Padrão & Valor $\mathbf{T}$ & Sig. \\
\hline (Constante) & 582,87 & 11,16 & 52,24 & 0,00 \\
\hline \multicolumn{5}{|c|}{ Dependência administrativa } \\
\hline Estadual & $-34,58$ & 11,16 & $-3,10$ & 0,00 \\
\hline Municipal & $-40,85$ & 11,15 & $-3,66$ & 0,00 \\
\hline \multicolumn{5}{|l|}{$\begin{array}{l}\text { Referência: } \\
\text { Federal }\end{array}$} \\
\hline \multicolumn{5}{|c|}{ Nível socioeconômico } \\
\hline Ausente & $-32,21$ & 0,67 & $-47,88$ & 0,00 \\
\hline Baixo & $-47,96$ & 0,61 & $-78,95$ & 0,00 \\
\hline Médio & $-26,14$ & 0,58 & $-44,94$ & 0,00 \\
\hline \multicolumn{5}{|l|}{ Referência: Alto } \\
\hline \multicolumn{5}{|l|}{ Infraestrutura } \\
\hline Ausente & $-33,05$ & 2,53 & $-13,06$ & 0,00 \\
\hline Baixa & $-34,64$ & 0,83 & $-41,72$ & 0,00 \\
\hline Média & $-11,38$ & 0,55 & $-20,87$ & 0,00 \\
\hline \multicolumn{5}{|l|}{ Referência: Alta } \\
\hline \multicolumn{5}{|c|}{ Formação docente } \\
\hline Baixa & $-19,31$ & 0,58 & $-33,07$ & 0,00 \\
\hline Média & $-6,25$ & 0,48 & $-13,10$ & 0,00 \\
\hline \multicolumn{5}{|l|}{ Referência: Alta } \\
\hline \multicolumn{5}{|c|}{ Complexidade da gestão } \\
\hline Ausente & 1,60 & 2,56 & 0,62 & 0,53 \\
\hline Baixa & 9,79 & 0,58 & 17,03 & 0,00 \\
\hline Referência: Alta & & & & \\
\hline
\end{tabular}

Fonte: Elaboração própria.

Todos os coeficientes são significativos, refletindo simplesmente o grande número de escolas incluídas na análise. Como o desvio-padrão dos desempenhos das escolas é de 55 pontos e todas as variáveis incluídas na regressão são indicadoras, cada coeficiente, que mede o efeito de cada fator, controlado pelos outros, deve ser comparado com esse valor para se ter uma avaliação de seu impacto substantivo. Cohen (1988) diz que valores menores que 0,2 devem ser considerados pequenos e maiores que 0,8 devem ser considerados grandes.

Os estudantes das redes municipais e estaduais têm desempenho substancialmente menor do que os da rede federal. Isso é explicado pelos processos de seleção usados para admissão nessa rede. Mesmo quando há sorteio de vagas, os selecionados na rede federal constituem um grupo de estudantes com melhor perspectiva de aprendizado, tendo em vista que são filhos de famílias que valorizam a escola, fato demonstrado pela sua busca da vaga. Os estudantes das escolas municipais têm, tipicamente, desempenho inferior aos das escolas estaduais. 
O nível socioeconômico (NSE) da escola está também associado a uma grande diferença de desempenho. Os estudantes de nível baixo e médio têm desempenhos muito menores do que os de NSE mais alto, tomado como referência. Nota-se também que os estudantes das escolas para as quais a medida do NSE não está disponível têm desempenho muito mais baixo do que os estudantes das escolas de NSE alto, indicando que a mera ausência da medida de NSE revela uma situação de vulnerabilidade.

A associação entre a infraestrutura das escolas e o desempenho de seus estudantes na ANA é também muito evidente. De forma particular, os estudantes de escolas com baixo valor do indicador de infraestrutura têm desempenhos menores. Ou seja, os estudantes que frequentam escolas com pior infraestrutura têm uma desvantagem estrutural. A associação do desempenho com a qualificação docente é também expressiva, indicando que os estudantes cujas professoras têm formação específica estão mais bem atendidos.

O efeito do indicador de complexidade escolar vai na direção esperada, isto é, os estudantes das escolas com menor complexidade de gestão, que se concentram nos anos iniciais do ensino fundamental, têm melhor desempenho. Isso pode estar associado ao fato de que, na ausência de outras etapas, a alfabetização ganha proeminência, o que se reflete no aprendizado dos estudantes.

\section{Considerações finais}

Apesar dos muitos avanços observados nas últimas décadas, o problema da alfabetização persiste no País. Neste início do século 21, as crianças brasileiras estão matriculadas na escola, mas muitas não aprendem ou aprendem muito lentamente. Diante disso, é muito pequeno o número de crianças que, depois de três anos de escolarização, têm desempenho adequado em um teste de Leitura com nível de exigência absolutamente padrão, como foi a ANA.

As evidências obtidas com as análises apresentadas neste artigo revelam que intervenções em fatores escolares estão associadas a proporções mais altas de estudantes em níveis mais altos de aprendizado. De fato, foi demonstrado que, depois de controladas pelo nível socioeconômico dos estudantes, as escolas cujo indicador de formação docente é mais alto, bem como aquelas cujo indicador de complexidade da gestão é mais baixo, possuem mais estudantes nos níveis mais altos de aprendizados. Além disso, os resíduos do modelo de regressão, usado para a análise da associação entre os fatores escolares e os resultados dos estudantes, podem ser utilizados para identificar escolas com alto efeito positivo, isto é, escolas que conseguem melhorar o nível de aprendizado de seus estudantes além do que seria esperado pelas suas características sociais. Embora não seja adequado citar nominalmente essas escolas, ressalta-se que há exemplos desse tipo em todas as unidades da Federação. São escolas exemplares e merecem estudos de caso que registrem as boas políticas educacionais nelas utilizadas sistemática e continuadamente. 
No entanto, a evidência mostra também as enormes desigualdades estruturais do sistema educacional brasileiro. Estar matriculado em uma escola com as melhores características pode significar uma mudança de desempenho enorme. Isso não é razoável em um sistema cuja função deveria ser a de garantir direitos para todos. Nessa circunstância, as diferenças entre escolas deveriam ser modestas.

Vale ressaltar, por fim, que as mudanças introduzidas pela Base Nacional Comum Curricular (BNCC) no ensino fundamental ao final de 2017, em particular em relação à alfabetização, devem impactar o formato tanto das avaliações externas somativas como das processuais formativas. Quanto à avaliação externa nacional, foi tomada a decisão de modificar o ano escolar de aplicação da avaliação de alfabetização, que passa a ser ao final do $2^{\circ}$ ano do ensino fundamental. Em 2019, inclusive, o Saeb-Alfabetização foi aplicado pelo Inep para crianças de $2^{\circ}$ ano do ensino fundamental de escolas públicas e particulares, com uma nova Matriz de Referência alinhada à BNCC. No momento da finalização do presente texto, ainda não havia ocorrido a divulgação dos resultados do Saeb 2019, previstos para o segundo semestre de 2020.

\section{Referências bibliográficas}

BARROS, G. T. F. et al. Indicador de nível socioeconômico dos inscritos no Enem. Brasília: Inep, 2019. (Série Documental. Textos para Discussão, n. 47).

BRASIL. Instituto Nacional de Estudos e Pesquisas Educacionais Anísio Teixeira (Inep). Avaliação Nacional da Alfabetização (ANA): documento básico. Brasília: Inep, 2013.

BRASIL. Instituto Nacional de Estudos e Pesquisas Educacionais Anísio Teixeira (Inep). Avaliação Nacional da Alfabetização (ANA): relatório 2013-2014: volume 1: da concepção à realização. Brasília: Inep, 2015a.

BRASIL. Instituto Nacional de Estudos e Pesquisas Educacionais Anísio Teixeira (Inep). Avaliação Nacional da Alfabetização (ANA): relatório 2013-2014: volume 2: análise dos resultados. Brasília: Inep, 2015b.

BRASIL. Instituto Nacional de Estudos e Pesquisas Educacionais Anísio Teixeira (Inep). Relatório Saeb/ANA 2016: panorama do Brasil e dos estados. Brasília, 2018.

BRASIL. Ministério da Educação (MEC). Portaria no 867, de 4 de julho de 2012. Institui o Pacto Nacional pela Alfabetização na Idade Certa e as ações do Pacto e define suas diretrizes gerais. Diário Oficial da União, Brasília, DF, 5 jul. 2012. Seção 1, p. 22.

BRASIL. Ministério da Educação (MEC). Portaria no 482, de 7 de junho de 2013. Dispõe sobre o Sistema de Avaliação da Educação Básica - Saeb. Diário Oficial da União, Brasília, DF, 10 jun. 2013. Seção 1, p. 17. 
COHEN, J. The effect size index: d. In: COHEN, J. Statistical power analysis for the behavioral sciences. $2^{\text {nd }}$ ed. Hillsdale: Lawrence Erlbaum Associates, 1988. p. 20-26.

FERRARO, A. R. Analfabetismo e níveis de letramento no Brasil: o que dizem os censos? Educação \& Sociedade, Campinas, v. 23, n. 81, p. 21-47, dez. 2002.

HOOVER, W. A.; PHILIP B. G. The simple view of reading. Reading and Writing, Dordrecht, v. 2, n. 2, p. 127-160, June 1990.

LOURENÇO FILHO, M. B. Estatística e educação. Revista Brasileira de Estudos Pedagógicos, Rio de Janeiro, v. 11, n. 31, p. 467-488, nov./dez. 1947.

MULLIS, I. V. S.; MARTIN, M. O. (Ed.). PIRLS 2016 Assessment Framework. $2^{\text {nd }}$ ed. Chestnut Hill: TIMSS \& PIRLS International Study Center, 2015.

ORGANISATION FOR ECONOMIC CO-OPERATION AND DEVELOPMENT (OECD). Pisa 2015: technical report. Paris: OECD, 2017.

PAIVA, V. Um século de educação republicana. Pro-Posições, Campinas, v. 1, n. 2, p. 7-18, jul. 1990.

RIBEIRO, S. C. A pedagogia da repetência. Estudos Avançados, São Paulo, v. 5, n. 12, p. 7-21, maio/ago. 1991.

SCARBOROUGH, H. S. Connecting early language and literacy to later reading (dis)abilities: evidence, theory, and practice. In: NEUMAN, S.; DICKINSON, D. (Ed.). Handbook for research in early literacy. New York: Guilford Press, 2001. p. 97-110.

SOARES, J. F. Índice de desenvolvimento da educação de São Paulo (Idesp): bases metodológicas. São Paulo Perspectivas, São Paulo, v. 23, n. 1, p. 29-41, jan./jun. 2009 .

SOARES, J. F.; ALVES, M. T. G.; XAVIER, F. P. Effects of Brazilian schools on student learning. Assessment in Education: Principles, Policy \& Practice v. 23, n. 1, 75-97, 2016.

SOARES, M. Alfabetização: a questão dos métodos. São Paulo: Contexto, 2016.

UNESCO. The plurality of literacy and its implications for policies and programs: position paper. Paris: Unesco, 2004.

UNESCO. Qualidade da infraestrutura das escolas públicas do ensino fundamental no Brasil: indicadores com dados públicos e tendências de 2013, 2015 e 2017. Brasília: Unesco, 2019. 
José Francisco Soares, doutor em Estatística, é professor emérito da Universidade Federal de Minas Gerais (UFMG). Foi presidente do Inep de fevereiro de 2014 a fevereiro de 2016. Suas áreas de pesquisa incluem métodos em avaliação educacional, construção de indicadores educacionais e medidas de desigualdade em Educação.

francisco-soares@ufmg.br

Luana Bergmann, pedagoga e mestre em Educação pela Universidade Federal de Santa Catarina (UFSC), é membro da carreira de Pesquisadores do Inep desde 2010, onde, entre outras posições, no período de 2016 a janeiro de 2019 esteve à frente da Diretoria de Avaliação da Educação Básica, área técnica responsável por diversas ações de impacto nacional e internacional, entre as quais se destacam o Sistema de Avaliação da Educação Básica (Saeb), o Programa Internacional de Avaliação de Estudantes (Pisa) e o Exame Nacional do Ensino Médio (Enem).

luana.soares@inep.gov.br

Recebido em 29 de março de 2020

Aprovado em 15 de julho De 2020 